\title{
Ocean Cities Structural Integrity and Health Monitoring System
}

\section{Système d'intégrité Structurale et de Surveillance de sécurité des cités marines}

\author{
Jay-Chung Chen * and James L. Beck ** \\ Research Centre, Hong Kong University of Science and Technology, Kowloon, Hong Kong
}

Michelle H. Teng ***

Research Centre, Hong Kong University of Science and Technology, Kowloon, Hong Kong

\section{INTRODUCTION}

Over the last decade, as people realize more and more the great potential to utilize the vast ocean resources to benefit human society, many studies have been carried out to propose and design very large floating structures (VLFS). These structures are usually proposed for use as floating airports, research and recreational facilities, military bases and ocean cities for human inhabitation. Promotion of ocean cities has received support not only from academic scientists, but also from governments, private industry and the United Nations.

(*) Director, also Professor of Mechanical Engineering.

(**) Visiting Research Engineer, also Associate Professor of Civil Engineering. California Institute of Technology.

(***) Consultant, also Assistant Professor of Civil Engineering. University of Hawaii.

\begin{abstract}
The dominant difference between a floating ocean city and a conventional floating structure is that the size of an ocean city is substantially larger; for example, it can be as large as several square kilometers. Due to this large size, the corresponding structural and hydrodynamic analyses for the floating structure supporting the ocean city become much more complex, and conventional design principles for ordinary offshore structures are no longer appropriate. The large size also makes it impossible to construct the structure in one piece on land and then float it to the site. Instead, modules of some optimal scale will need to be constructed separately on land and then assembled together in the ocean. Also, because of the large size of the floating structure it cannot be treated as a rigid body ; instead, both its global and local dynamic response characteristics need to be considered, along with their excitation by the environmental and man-made loads acting on the structure. The most important of these loads are those arising from wave
\end{abstract}

\begin{abstract}
For obvious reasons, the structural integrity and health condition of ocean cities are important safety issues for viable human inhabitation. For large complex civil structural systems, structural health can be monitored by measuring its dynamic response to environmental or man-made loads acting on the system. The response can be continuously checked in relation to critical design levels. In the case that the structural response exceeds the design levels, the structural system should be immediately inspected for damage. However, structural systems can suffer damage from continual environmental degradation, even at low response amplitude levels. This damage can accumulate to such a stage that a failure may occur under a final loading which has an amplitude smaller than the critical design levels. If structural damage is not detected and corrected then it may progressively worsen and eventually cause catastrophic structural failure. Therefore, a methodology for monitoring structural integrity, in order to rapidly detect the occurrence and identify the location of damage, will be instrumental in assuring the safety of ocean cities. Such a concept for damage assessment is presented here based on measuring both structural response and environmental parameters which can be used to infer the exciting forces on the system. This concept is illustrated using simulation studies of a large suspension bridge being built in Hong Kong.
\end{abstract}


action ; in calculating these, the structure and the wave field must be treated as a coupled system, since the presence of such a large structure in the water will change the original wave field significantly [1 and 2].

The safety of offshore structures, such as oil and gas platforms, has always been an important issue, and for a floating ocean city intended for human inhabitation, the safety issue is even more critical. So far, most of the studies related to VLFS have focused on developing structural and hydrodynamic theories to predict structural response, while the concept of a practical system to monitor the health of floating structures has received little attention.

Larger complex structural systems, such as ocean cities, are expensive to construct, maintain, rehabilitate or replace, so it is important to secure their function, and to protect their occupants and the vast investments made in their construction and operation. It is increasingly recognised that such large systems can benefit from a comprehensive " health " monitoring system which automatically and immediately detects, locates and assesses any damage occurring in the structural system, where damage means the reduction of either the strength, the stiffness, or both, in any component or member.

The term «structural health monitoring " means diagnostic monitoring of the integrity or condition of a structure using a network of distributed sensors (e.g. accelerometers or strain gauges) in conjunction with an « intelligent » computer-based data processing system. For an ocean city, its function would be to provide rapid detection and assessment of structural damage due to longterm degradation from operational use and environmental effects such as corrosion or fatigue, as well as from extreme structural loading events, including storm-generated ocean waves, earthquake-generated tsunamis, hurricane winds, explosions and impact by floating objects.

Once damage is initiated, it will tend to propagate under the effect of continual environmental and man-made loads. Therefore, damage that is not immediately detected and rapidly repaired will be compounded and may even lead to eventual catastrophic structural failure which can threaten the integrity of the whole structural system. For safe operation of an ocean city, it is therefore important that the monitoring system provide information about the occurrence of damage in real-time so that rapid corrective action can be taken before the damage begins to spread.

In this paper, a structural health monitoring system is proposed that uses continual measurement and real-time analysis of dynamic (vibrational) response data from a comprehensively instrumented ocean city structural system. The monitoring system takes advantage of the continuous " ambient » response due to dynamic service and environmental loadings to infer whether damage or degradation has occurred in structural components. If damage is detected, a warning is generated, perhaps accompanied by a graphical display of the location and likely degree of damage on special monitoring screens at an Operations Center for the city. This information would allow remedial action to be taken before damage progresses to the stage where catastrophic failure may occur. In addition to its damage detection role, the acquisition of data relating to dynamic response and environmental loads can play a valuable role in improving the state of knowledge of structural performance, engineering design and construction practice for ocean cities.
Details of the proposed monitoring system are presented in the following sections along with a discussion on environmental loads whose real-time prediction or measurement can be used to enhance the operation of the structural health monitoring system.

\section{STRUCTURAL HEALTH MONITORING TECHNIQUES}

There are two basic approaches to structural health monitoring. The first is to measure the dynamic response of the structural system and check whether pre-set, design-based threshold levels have been exceeded anywhere in the structure. This approach is appropriate for sensing the occurrence of a severe loading event and for determining which parts of the structural system experienced « overloading " as a result. Of course, threshold exceedance does not necessarily imply that structural damage has occurred. Conversely, component or member failure from long-term environmental degradation may not be associated with any response threshold exceedance. This motivates the second approach which is to measure quantities more directly indicative of damage, such as excessive relative displacements between structural members, particularly at their connections.

The challenge in both of these approaches is that it is not possible to instrument all locations because of the large physical size and complexity of the structural system supporting the city. Not only are there too many locations of interest to place a sensor at each one, some locations will not even be accessible for sensor placement. However, by smart processing of sensor signals, excessive response and likely damage may be monitored at all locations. This is usually done by employing a numerical computer model, typically derived by the Finite Element Method, which describes the dynamic behavior of the structural system and which has been pre-calibrated using measured dynamic response due to external excitation from wind and waves, as well as internal vibration sources within the city.

For checking threshold exceedance everywhere, techniques have been developed to predict the response at unmonitored locations from the measured response, even though the exciting forces are not known [28]. For more directly addressing detection of structural damage, robust techniques have been developed for « inverting » dynamic response data to infer stiffness changes in the structural system, since damage is usually accompanied by a local loss of stiffness. This inversion is typically ill-conditioned in the presence of measurement noise and modelling errors and so it presents a specially challenging engineering problem. The ill-conditioning, and even nonuniqueness, of this inversion process introduces uncertainties which can be treated using a probabilistic framework $[29,30]$.

The inversion to detect and localize any stiffness loss is based on "updating " stiffness parameters in the precalibrated numerical structural model using experimentally measured data, a general process commonly known as system identification. A typical procedure involves a twostage process $[31,32]$. First, a modal test is performed on the structural system during which the response due to external excitations are measured. From the response data, the dynamic characteristics of the system such as the natural frequencies and mode shapes can be determined 
directly or through data processing techniques, depending on the test method employed. Because the natural frequencies and mode shapes of a structural system are functions of the system parameters such as the mass and stiffness, these system parameters may be estimated by « inverting " the dynamic modal characteristics in the second stage of the process.

Using similar concepts, attempts have been made in the past to develop techniques for using vibration measurements to evaluate the structural integrity of offshore oil and gas platforms [3-5]. Because of the adverse conditions in acquiring these measurements, the high redundancy of the structural system, the lack of sensors distributed over the full height of the structure and the poor signal-to-noise ratio compared with modern sensors, the methodology for detecting structural failures did not become mature.

On the other hand, in the aerospace industry, modal tests are performed on extensively instrumented spacecraft using precisely controlled excitations for determining natural frequencies, mode shapes, and damping. Here, the objective is to verify a mathematical model to be used in the loads analysis by comparing the dynamic characteristics obtained by a test to those predicted by the analytical model. The differences between the test and analysis results are then used to modify the mathematical model so that the model accurately predicts the test results [6-10].

However, for large complex structures such as tall buildings, long bridges, and very large floating structures, conventional modal testing using man-made external excitation is not feasible in general. Instead, environmental excitation such as wave and wind loads are used. In this case, the sensitivity of the stiffness inversion process can be enhanced by using as much information as possible about the dynamic loads on the structure which produces the measured dynamic response. Basically, this information makes it easier for the inversion methods to distinguish effects in the measured response due to changing dynamic characteristics of the structural system from those effects due to changing features in the excitation.

\section{III — DOMINANT ENVIRONMENTAL LOADS EXCITING OCEAN CITIES}

The environmental loads acting on a floating structure are induced by the interaction between the structure and fluid flows which include sea waves, winds and ocean currents. These loads act through both normal pressure forces and viscous shear forces and different hydrodynamic theories are required for different types of forcing. In general, for a very large floating structure, the structure and the fluid field are treated as a coupled system, and for design purposes, they are either determined through numerical simulation or by experiments and empirical formulas. However, for application to structural health monitoring, flow measurements and hydrodynamic theories must be combined in real-time to infer, or predict, the environmental loads acting on the structure, since it is normally not feasible to directly measure these loads.

\subsection{Forces induced by deep sea periodic waves}

The dominant environmental force that an ocean city will experience continuously is the force induced by regular periodic sea surface waves. To model this wave force, it is usually assumed that the sea water is incompressible and inviscid, and the flow irrotational. In this case, relatively simple potential theory can be used to solve for the resultant force based on knowledge of the surrounding flow field. A linear theory is valid for wave amplitude much smaller than the water depth. However, since an ocean city will be located in deep ocean, this theory is adequate to study wave height as large as 10 meters. If the ocean waves in reality are irregular waves consisting of different frequencies, then the above theory is still valid but Fourier analysis needs to be added into the modeling.

\subsection{Forces induced by wind}

There are no theoretical solutions to predict the wind force acting on a floating structure. Usually the wind stress is written as function of wind field, wind coefficient and air density and these relationships are determined by experiments or empirical estimates [25].

\subsection{Forces induced by current}

In the ocean, currents are generated by many factors such as tides, winds, surface waves and temperature variations. The impact of an ocean current on a floating structure appears in two forms: the viscous drag force and the oscillation excitation of the structure due to vortex shedding in the wave. At the current stage, neither phenomena can be modelled theoretically; instead, their effects can only be examined through experiments and empirical expressions.

To apply the methods for predicting the environmental forcing functions, appropriate environmental parameters must be measured and recorded. These include incoming wave height, frequency and propagation direction, and wind and current speed and direction. To measure the wave height and frequency, a pressure sensor can be suspended from a buoy at a sufficient depth in the ocean. To determine the wave direction, a standard X-band radar can be operated from an elevated position on the ocean city. The surface current can be measured by drifter or buoy current gauges. For wind measurement, simple wind meters can be distributed at different locations on and around the ocean city to record the wind data. These measured environmental parameters will be input in real-time into the hydrodynamic and structural models to predict the structural loads.

A large number of references are available for the subject, Refs. 11 to 23 are a selected few.

\section{ILLUSTRATIVE LARGE SCALE STRUCTURE EXAMPLE $\square$}

Although the application of a structural health monitoring system to an ocean city must wait until such structural systems become a reality, the ideas proposed here may be tested on a long suspension bridge currently under construction in Hong Kong. In this case, the dominant environmental excitation is wind loadings, including seasonal typhoons. This bridge is used here to illustrate the concept of structural health monitoring [24]. 
Figure $I$ shows the schematics of the bridge under construction and figure 2 is a photo of the actual construction activity. The bridge is designed for both rail and automobile traffic and it connects the new Hong Kong International Airport at Chek Lap Kok to downtown Hong Kong.

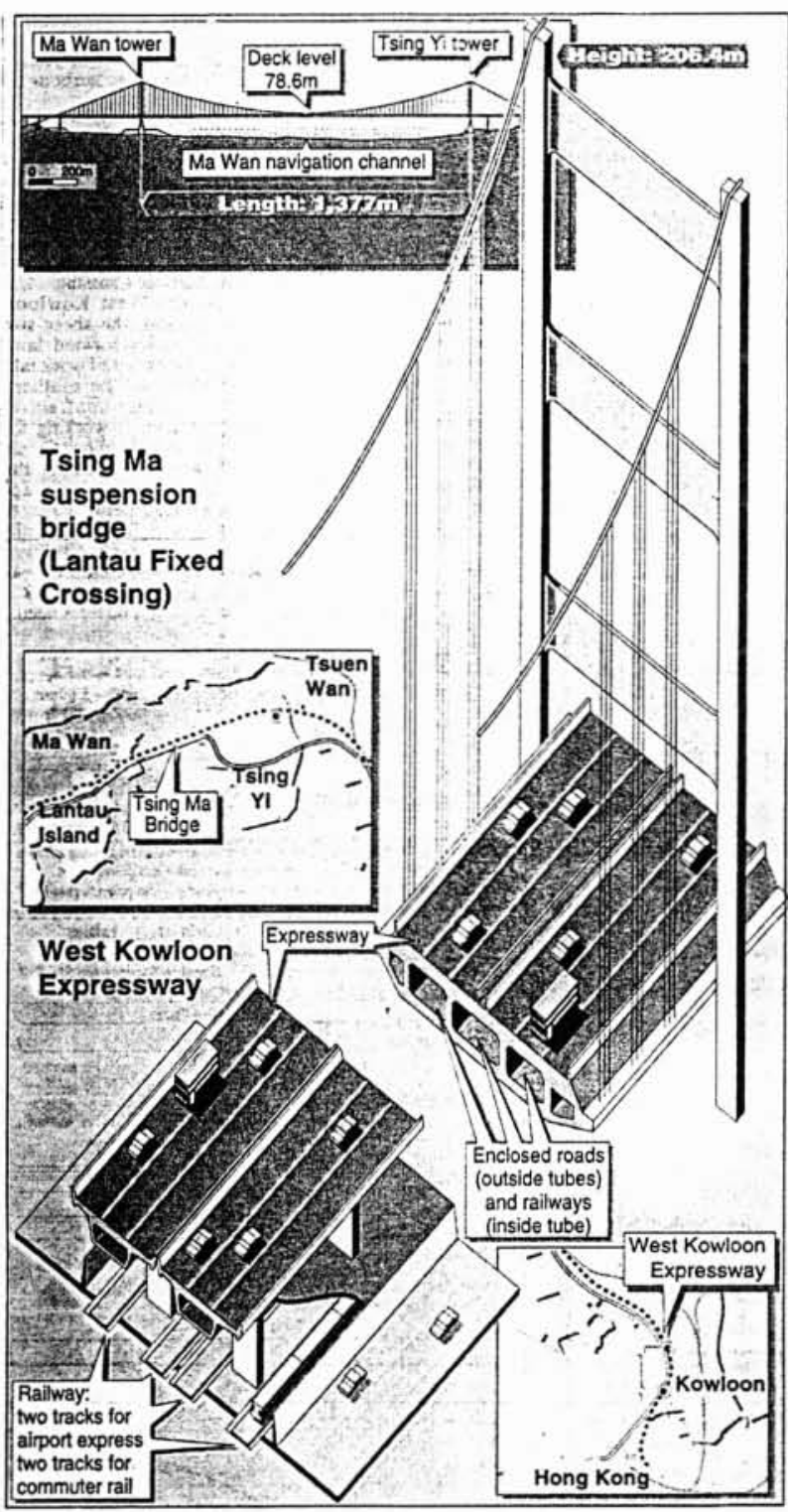

\section{Long Suspension Bridge.}

A finite element model using the NASTRAN code is established for the purpose of studying the dynamic characteristics of the bridge as well as for calculating the response due to external loads. The model consists of 1,794 degrees-of-freedom (DOF) and is shown schematically in figure 3 .

The sensitivity of the dynamic characteristics of the bridge to its major structural elements is studied. Using the model to simulate possible damage in various components (for example, the bridge supports, cables, or main deck), the dynamic characteristics of the "damaged » bridge can

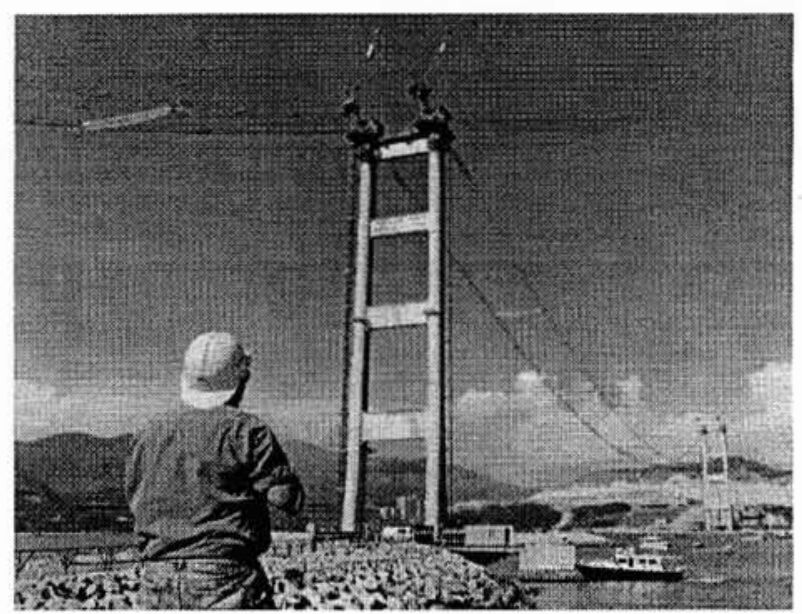

2. Bridge construction.

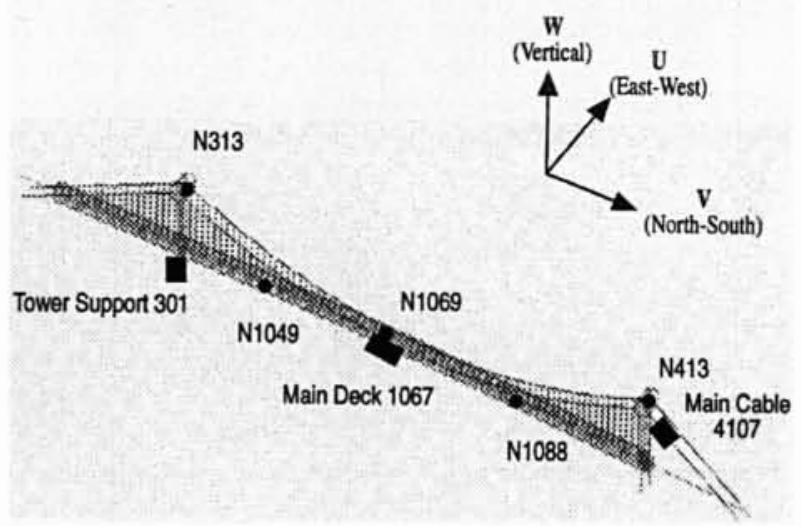

3. Bridge finite-element model.

be obtained. This provides a basis for determining which structural members can be reliably identified as «damaged " from observed changes in the dynamic characteristics of the bridge [8].

Although the bridge has not yet been completed, turbulence measurements in the forms of wind velocity have been conducted by an instrumented aircraft (fig. 4) flying in the vicinity of the bridge during selected meteorological events. Figure 5 shows the airborne measured wind velocity during typhoon Russ on June 5-6, 1994.

Figure 6 is the power spectra plot of the three wind velocity components. It is clear that the wind velocity contains substantial energy component in the low frequency regime which overlaps the bridge natural frequencies. These wind velocities will be converted to aerodynamic loads based on the theory of wind loadings [25] which will be the external forcing functions for the bridge. However, since these wind velocity measurements were made on a moving platform instead of the stationary sensors, only their frequency content is meaningful.

For the purpose of seeking frequency response functions, these wind velocities are applied directly to the top of the support towers in the lateral direction (U) and to the three discrete points on the deck in the lateral and vertical directions ( $\mathrm{U}$ and $\mathrm{W}$ respectively). 


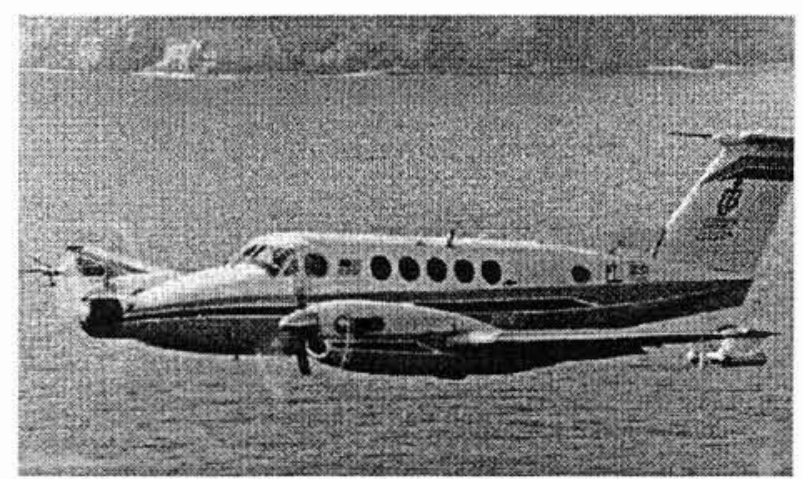

4. Instrumented aircraft.

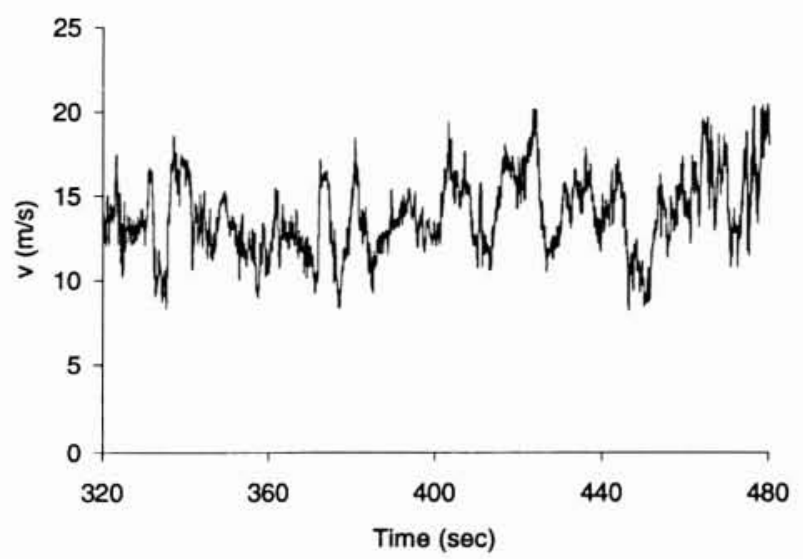

5. Wind velocity during typhoon Russ.

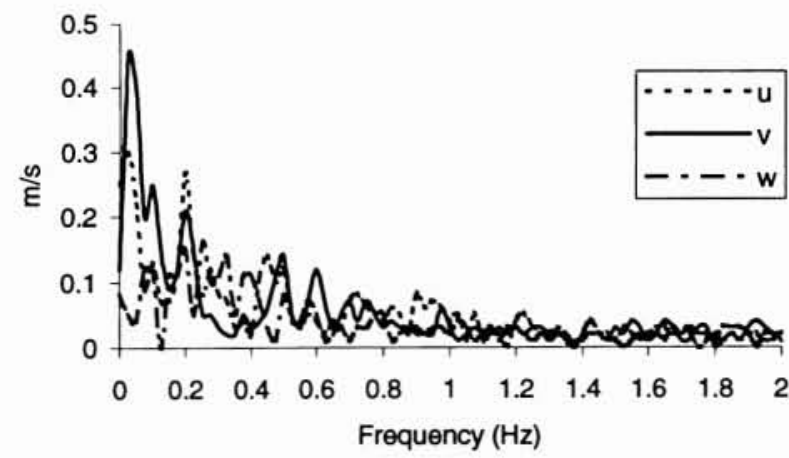

6. Wind velocity spectra.

The dynamic responses of the bridge due to the « measured " external forcing functions are obtained, for the " healthy " bridge as well as the "damaged " bridge. These dynamic responses are then utilized to obtain the corresponding dynamic characteristics. Special attention is paid to particular features of the forcing functions with respect to the feasibility of extracting the natural frequencies and mode shapes [26].

The proposed structural damage detection methodology is based on comparisons of the structural dynamic characteristics of the " healthy " bridge versus the " damaged " bridge derived from the dynamic response due to the actual forcing functions. Damage in the form of «stiffness re- duction " can be inferred by the results of a sensitivity study or by an inverse calculation [27, 32].

For illustrative purposes, "damage " represented by a $50 \%$ stiffness reduction at element 301 of the support tower was implemented in the model. Figure 7 shows the simulated responses of the "damaged" and «undamaged " bridges at node 1049 which is at quarter deck position (fig. 3). It is sufficient here to conclude that significant differences in response spectra can be obtained. It is these types of differences in dynamic response which will provide indications of structural damage. In [24] the damage locations and the extent of damage were identified by considering changes in the dynamic characteristics such as the natural mode shapes.

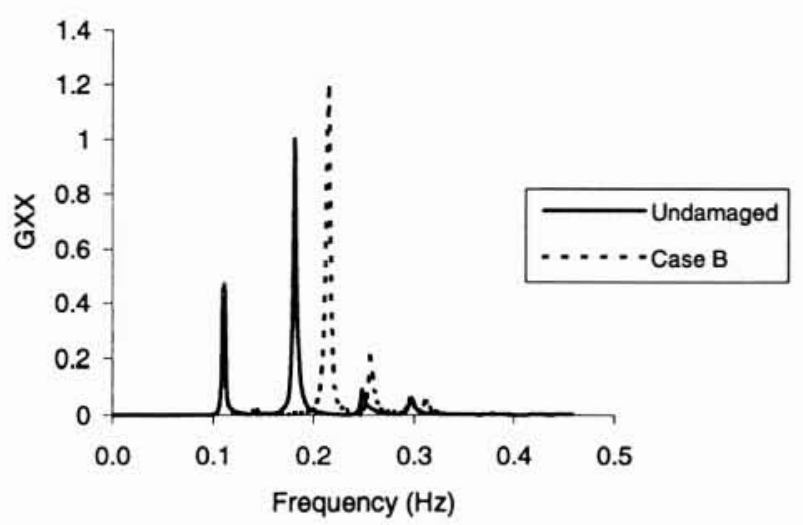

7. Frequency response function comparison of node 1049-U direction.

\section{D PROPOSED STRUCTURAL INTEGRITY AND HEALTH MONITORING SYS- TEM}

The proposed monitoring system consists of two integrated functions: one for a real-time alerting system, and the other for a health monitoring system. The purpose of the real time alerting system is to provide warnings whenever critical response level thresholds are exceeded due to extreme wave, wind and other loading. The purpose of the health monitoring system is to detect changes in the structural behavior of the ocean cities which may be interpreted as precursors to more serious structural damage or failure so that preventative repair and retrofit measures can be undertaken in a timely and cost effective manner. Figure 8 shows such a monitoring system proposed for ocean cities.

The monitoring system will meet the following objectives :

- Monitor environmental parameters to determine the loading condition.

- Monitor and evaluate the structural response of the ocean city under a range of loading conditions, based on measured structural factors such as element loads, strains, displacements, accelerations, etc..., and provide for realtime display of critical information.

- Identify long term degradation of the ocean city, suspected locations of deterioration, suspected locations of excessive deformation or stress, or regions of damage and 


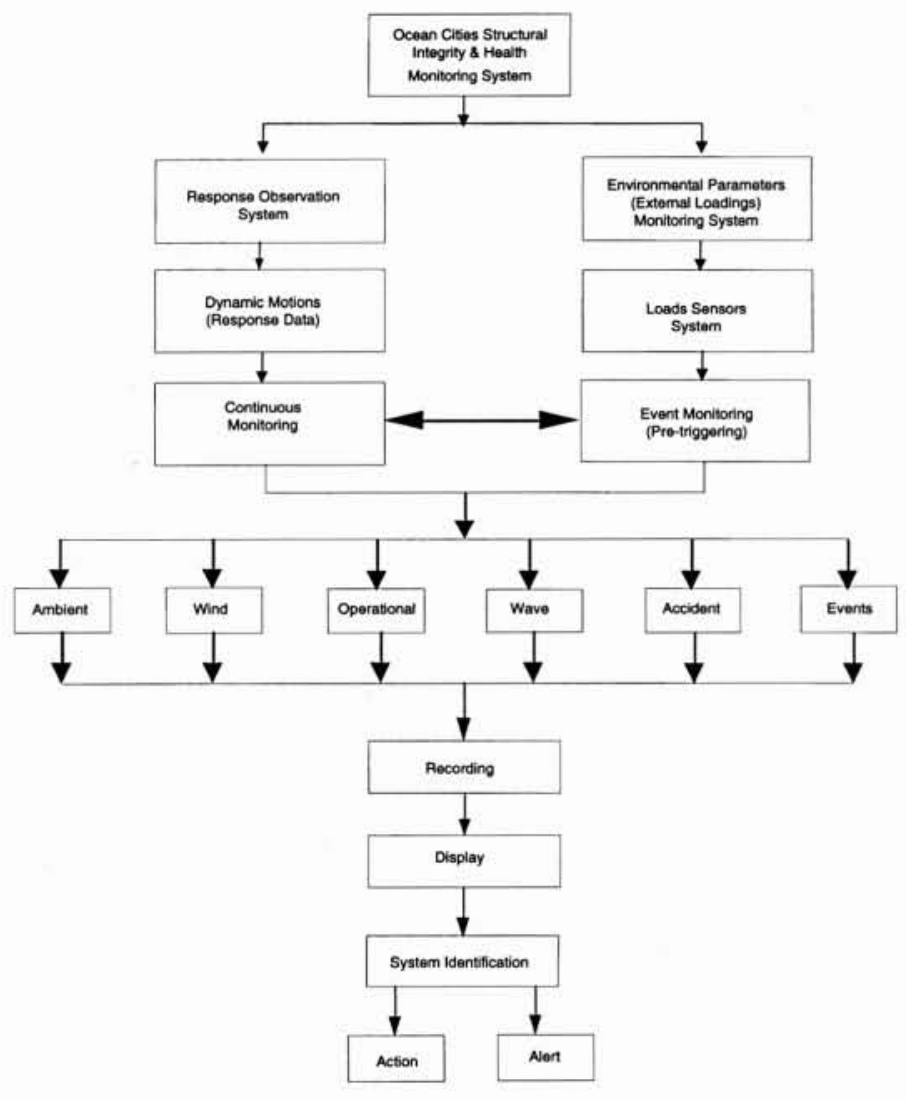

8. Proposed ocean cities structural integrity and health monitoring system.

provide a graphical interface for presenting critical information, such as changes in natural frequencies and mode shapes, and local changes in stiffness.

- Provide a rational basis for operational decisions concerning structural safety, inspection and maintenance, thereby improving safety, reliability, user comfort and efficiency of operation.

- Provide data to refine/update the analytical models of the ocean city for structural analysis by using structural identification techniques.

- Provide basic data and information for modification and improvements of ocean cities construction codes.

The monitoring system will involve five functional components :

Component 1 : Sensing: Measurement of relevant environmental inputs and structural response

Component 2: Acquisition: Recording of measured data for real time and longer-term analysis

Component 3: Processing and Analysis: For Real Time Alerting and longer-term Health Monitoring

Component 4 : Displays : Presentation of processed data for Real Time Alerting and longer-term Health Monitoring in easily understood form

Component 5: Action Strategies : Safety decisions, disaster recovery and maintenance, based on damage detection and criteria evaluation

These components are illustrated in figure 9 " System Function Diagram ».

\section{VI $\square$ CONCLUDING REMARKS}

The proposed ocean cities structural integrity and health monitoring system is based on experience being gained from other large complex civil structural systems. It is very preliminary in nature and further refinement will be required. Nevertheless, the presently proposed system can be taken as a basic framework in which the fundamental objectives can be achieved.
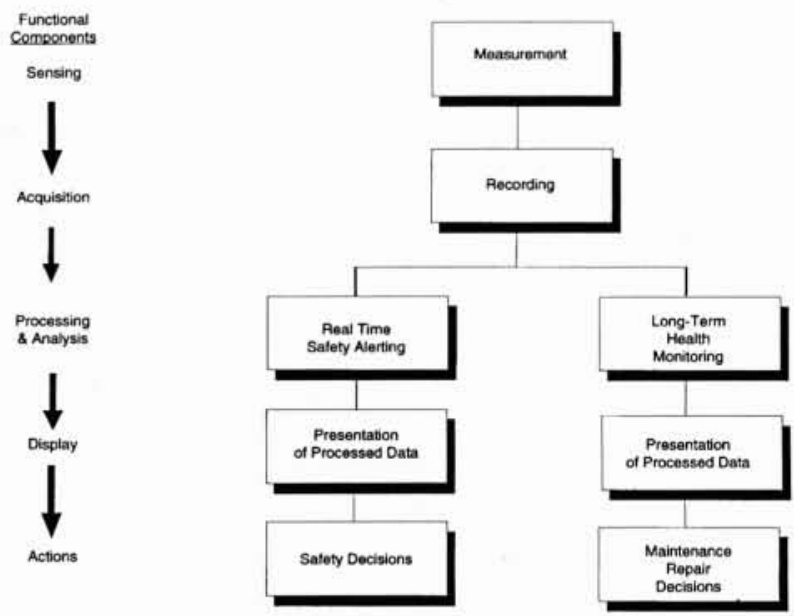

9. System function diagram. 


\section{References}

[1] Bretz G., McAllister K. and VAughters T. - «Technological alternatives to overseas basing-concepts in naval offshore basing ", Proc. First Int. Workshop on Very Large Floating Structures (sponsored by NSF), University of Hawaii, April 24-26, 1991 , pp. 379-395.

[2] ERTEKIN R.C. - «Current and future directions in very large floating structure research and development, keynote lecture ", Proc. TECHNO-OCEAN'94, Kobe, Japan, Oct. 26-29, 1994, pp. 23-29.

[3] VANDIVER J.K. - « Detection of Structural Failure on Fixed Platforms by Measurement of Dynamic Response ", Proceedings of the Offshore Technology Conference, Vol. 2. Paper OTC 2267, May 1975, pp. 243-252.

[4] Wojnarowski M.E., StIAnsen S.G. and Reddy N.E. «Structural Integrity Evaluation of a Fixed Platform Using Vibration Criteria ", Proceedings of the Offshore Technology Conference, Vol. 3, Paper OTC 2909, May 1977, pp. 247. 256.

[5] Coppolino R.N. and RUBIN S. - « Detectability of Structural Failures in Offshore Platforms by Ambient Vibration Monitoring ", Proceedings of the Offshore Technology Conference, Vol. 1, Paper OTC 3865, May 1980, pp, 101-110.

[6] THOREH A.R. - «Derivation of Mass and Stiffness Matrices from Dynamic Test Data », AIAA Paper 72-346, April 1972.

[7] BERMAN A. and FLANNELLY W.G. - « Theory of Incomplete Models of Dynamics Structures ", AIAA Journal, Vol. 9. pp. 1481-1487, Aug. 1971.

[8] ChEN J.C. and GARBA J.A. - « Analytical Model Improvement Using Modal Test Results ", AIAA Journal, Vol. 18. pp. 684-690, June 1980.

[9] Chen J.C., Peretti L.F. and Garba J.A. - « Spacecraft Structural System Identification by Modal test ", Journal of Spacecraft and Rockets, Vol. 24, pp. 90-94, Jan-Feb, 1987.

[10] CHEN J.C. - $\propto$ Analytical Model Accuracy Requirements for Structural Dynamic Systems », Journal of Spacecraft and Rockets, Vol. 21, pp. 366-373, July-Aug, 1987.

[11] ERTEkin R.C., Riggs H.R., Che X.L. and DU S.X. (1993). — « Efficient methods for hydroelastic analysis of very large floating structures ", J. Ship Research, 37(1), 58-76.

[12] ERTEKIN R.C. and WANG S.Q. (1994).- « Hydroelastic response of a floating runway ", Hydroelasticity in Marine Technology, Faltinsen et al. (eds), Balkema Publishers, the Netherlands, pp. 389-400.

[13] FALtinsen O.M. (1990), - Sea loads on ships and offshore structures, Cambridge University Press.

[14] GuPTA A. and SINGH R.P. (1986), - Fatigue behaviour of offshore structures, Springer-Verlag.

[15] MAMIDIPUdi P. and WeBsTer W.C. (1994). - « The motions performance of a mat-like floating airport », $\mathrm{Hy}$ droelasticity in Marine Technology, Faltinsen et al. (eds), Balkema Publishers, the Netherlands, pp. 363-375.

[16] SORENSEN R.M. (1993). - Basic wave mechanics for coastal and ocean engineers, John Wiley and Sons, Inc..

[17] StANDing R.G., WILls J.A.B. and Singh S. (1990). «Wind loading and dynamic response of a floating production platform in waves ", Environmental Forces on Offshore Structures and Their Prediction, Kluwer Academic Publishers, the Netherlands, pp. 351-382.
[18] TAKAKI M. and TANGO Y. (1994). - « Wave drifting forces on multiple connected floating structures », Hydroelasticity in Marine Technology, Faltinsen et al. (eds), Balkema Publishers, the Netherlands, pp. 403-415.

[19] TUCKER M.J. (1991). - Waves in ocean engineeringmeasurement, analysis, interpretation. Ellis Horwood Publisher, New York.

[20] WANG D.Y., RIGGS H.R. and ERTEKIN R.C. (1991), «Three-dimensional hydroelastic response of a very large floating structure ", J. Offshore and Polar Engn., 1(4), 307. 316.

[21] WINKLER R.S. - « Positioning of very large floating structures ", Proc. First Int. Workshop on Very Large Floating Structures (sponsored by NSF), University of Hawaii, April 24-26, 1991, pp. 117-131.

[22] WU Y.S., WANG D.Y., RIGGS H.R. and ERTEKIN R.C. (1993). - «Composite singularity distribution method with application to hydroelasticity ", Marine Structures, 6, 143-146.

[23] ZHAO W.G. and BAKER M.J. (1990). — «A new stress-range distribution model for fatigue analysis under wave loading ", Environmental Forces on Offshore Structures and Their Prediction, Kluwer Academic Publishers, the Netherlands, pp. 271-291.

[24] CHEN J.C. - «Structural Damage Detection For Long Suspension Bridge Under Aerodynamic Loads », presented at AIAA/ASME Adaptive Structures Forum, April 12-13. 1995, New Orleans, LA, USA.

[25] SCANLAN R.H. and JONES N.P. (1990). - « Aeroelastic analysis of cable-stayed bridges ", Journal of Structural Engineering, ASCE, 116(2): 279-297.

[26] CHEN J.C. and GARBA J.A. - «Structural Damage Assessment Using A System Identification Technique », presented at the International Workshop on Structural Safety Evaluation Based on System Identification Approach, Pfalzakademie, Lambrecht, Federal Republic of Germany, June 29-July 1, 1987.

[27] Chen J.C. and Garba J.A. - « On-Orbit Damage Assessment for Large Space Structures ", AlAA Journal, Vol. 26, No. 9, pp. 1119-1126, Sept, 1988.

[28] Levine-West M.B. and Milman M. - «Mode Shape Expansion Techniques for Prediction ", Proceedings First World Conference on Structural Control, Pasadena, California, August 1994.

[29] Katafygiotis L.S. and BECK J.L. - $\propto$ Probabilistic Approach to Structural Health Monitoring from Dynamic Testing ", Proceedings International Workshop on Technology for Hong Kong's Infrastructure Development, Hong Kong University of Science and Technology, December 1991.

[30] BECK J.L. and KATAFYGIOTIS L.S. - « Probabilistic system Identification and Health Monitoring of Structures ", Proceedings Tenth World Conference on Earthquake Engineering. Madrid, Spain, July 1992.

[31] BECK J.L., MAY B.S. and POLIDORI D.C. - « Determination of Modal Parameters from Ambient Vibration Data for Structural Health Monitoring ", Proceedings First World Conference on Structural Control, Pasadena, California, August 1994.

[32] BECK J.L., VANiK M.W. and KatAFYGiotis L.S. - « Determination of Stiffness Changes from Modal Parameters Changes for Structural Health Monitoring ", Proceedings First World Conference on Structural Control, Pasadena, California, August 1994. 